\title{
Novel Protocols for the Catalytic Oxidation of Primary Amines to Imines
}

\author{
Martine Largeron*[a] \\ Dedicated to Professor Maurice-Bernard Fleury on the occasion of his $79^{\text {th }}$ birthday
}

Keywords: Amine / Imine / Oxidation / Metal catalysis / Metal-free catalysis / Photocatalysis / Bioinspired catalysis

The catalytic oxidation of amines to imines is of current and intense interest owing to the importance of imines as pivotal intermediates in the synthesis of fine chemicals and numerous biologically active compounds. Whereas considerable efforts were made to develop efficient methods for the oxidation of secondary amines to imines, until recently little attention was given to the oxidation of primary amines, probably because the generated imines are intermediate products that are easily dehydrogenated to nitriles. A surge of activity in this area originates with the discovery of new catalytic systems which allow the oxidation of primary amines to imines under green conditions. This microreview focuses on the major achievements during the last five years. [a] UMR 8638 CNRS-Université Paris Descartes, Paris Sorbonne Cité, Faculté des Sciences Pharmaceutiques et Biologiques,

4 avenue de l'Observatoire, 75270 Paris Cedex 06, France

Fax: +33144073588

E-mail: martine.largeron@parisdescartes.fr

Homepage: http://www.ssmip.cnrs.fr

\section{Introduction}

Imines are pivotal synthetic intermediates in a plethora of reactions such as reductions, additions, condensations, and cycloadditions and are essential pharmacophores in numerous biologically active compounds. ${ }^{[1]}$ The traditional condensation of amines with carbonyl compounds has long been considered as the most simple way to prepare imines. Because aldehydes are extremely reactive and thus difficult to handle, a powerful alternative strategy involves the cross-coupling between amines and alcohols through catalytic alcohol activation by temporary oxidation to an aldehyde. ${ }^{[2]}$ Amines are easily accessible compounds which can also be attractive precursors for imines by oxidation. In recent years, efficient catalytic methods have been developed for the oxidation of secondary amines to imines. ${ }^{[3]}$ One of the most elegant homogeneous systems is the biomimetic catalytic aerobic oxidation of secondary amines involving ruthenium amine complexes as key intermediates. ${ }^{[3 \mathrm{~d}]}$ This methodology, which tolerates important substrates classes, affords both ketimines and aldimines in good yields and with high selectivity. Comparatively little attention was devoted to the oxidation of primary amines, probably because the generated imines, in which a second $\alpha$-amino hydrogen is available, are generally intermediate products that are rapidly dehydrogenated to nitriles (Scheme 1). ${ }^{[3 b, c, i, 4]}$

$$
\mathrm{R} \mathrm{NH}_{2} \stackrel{[\mathrm{O}]}{\longrightarrow} \mathrm{R} \curvearrowright \mathrm{NH}^{[\mathrm{O}]} \longrightarrow \mathrm{R} \rightleftharpoons \mathrm{N}
$$

Scheme 1. Oxidative transformations of primary amines

Subsequent advances have been dominated by the development of new catalytic processes which allow the aerobic oxidation of primary amines to imines under mild conditions. This microreview concentrates on the major achievements which cover literature published between 2008 and the beginning of 2013. Although most of the new methods are also applicable to the oxidation of secondary amines, only the oxidation of primary amines is presented. The microreview is organized into four sections for metal-catalyzed, metal-free, photocatalyzed and bioinspired reaction types.

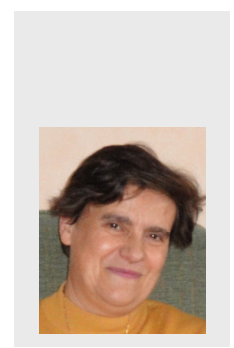

Martine Largeron graduated from the Pierre et Marie Curie University (Paris 6), where she also received her PhD prepared under the guidance of Prof. Maurice-Bernard Fleury. After a post-doctoral work at Rhone Poulenc Rorer (now Sanofi), she was enlisted as a researcher at CNRS and worked at the Paris Descartes University (Paris 5). In 2004, she became Research Director at CNRS. Her current research is focused on the discovery of bioinspired oxidation catalysts for synthetic applications. She was awarded from the French Society of Chemistry in 1990 and 1995 and from the National Academy of Medicine in 2004. Since 2012, she is a member of the National Academy of Pharmacy. 


\section{Metal-Catalyzed Oxidation Reaction}

\section{Gold-catalyzed aerobic oxidation}

The ability of ruthenium to oxidize, with high selectivity, primary amines to the corresponding nitriles led to examine the activity of other metal catalysts such as gold. ${ }^{[5]}$ A key difference between the gold-based systems and those involving ruthenium is that primary amines yield coupled imines products in place of nitriles. Accordingly, Angelici and co-workers reported a gold powder $(50 \mu \mathrm{m}$ size)-catalyzed aerobic oxidative homocoupling of primary amines to give imines, in toluene at $100^{\circ} \mathrm{C}$, under $1 \mathrm{~atm}$ of molecular oxygen. Further, they demonstrated that aluminasupported gold ( $\left.5 \% \quad \mathrm{Au} / \mathrm{Al}_{2} \mathrm{O}_{3}\right)$ nanoparticles (50-150 nm size) were much more active than the gold powder under the same experimental conditions. ${ }^{[5 b]}$ High yields of the imine products (Table 1) were then obtained from benzylamine substrates at the exclusion of $p$-chlorobenzylamine for which the yield decreased to $59 \%$. As earlier reported for the secondary amines, ${ }^{[3 \mathrm{~g}]}$ the oxidation of aliphatic $n$-hexylamine resulted in lower yield of the imine product (29\%).

Table 1. Gold-catalyzed aerobic oxidation of primary amines to imines.

$$
\begin{aligned}
& \mathrm{Au} / \mathrm{Al}_{2} \mathrm{O}_{3} \text { or } \mathrm{Au} \text { (powder) }
\end{aligned}
$$

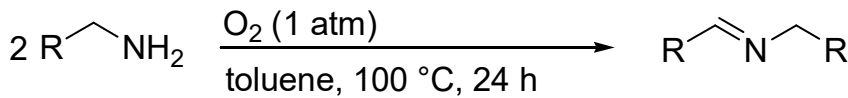

\begin{tabular}{llll}
\hline Entry & $\mathrm{R}$ & $\begin{array}{l}\text { Yield }[\%]^{[a]} \\
\text { Au powder cat. }\end{array}$ & $\begin{array}{l}\text { Yield }[\%]^{[\mathrm{b}]} \\
\mathrm{Au} / \mathrm{Al}_{2} \mathrm{O}_{3} \text { cat. }\end{array}$ \\
\hline 1 & $\mathrm{Ph}$ & 56 & 92 \\
2 & $p-\mathrm{Me}_{-} \mathrm{C}_{6} \mathrm{H}_{4}$ & 61 & 96 \\
3 & $p-\mathrm{Cl}_{2} \mathrm{C}_{6} \mathrm{H}_{4}$ & 7 & 59 \\
4 & $\mathrm{C}_{5} \mathrm{H}_{11}$ & 5 & 29 \\
\hline
\end{tabular}

[a] Gold powder $(1 \mathrm{~g}) ;[\mathrm{b}] 5 \% \mathrm{Au} / \mathrm{Al}_{2} \mathrm{O}_{3}$.

Two reaction pathways have been proposed for the goldcatalyzed aerobic oxidation of primary amines to imines (Scheme 2). Both involve oxidative dehydrogenation of the amine to the methanimine intermediate $\mathrm{RCH}=\mathrm{NH}$, which further reacts with a second molecule of primary amine, or with water, to finally afford the expected coupled imine. As yet, there is no conclusive experimental evidence to distinguish between these two pathways. ${ }^{[5 \mathrm{a}]}$

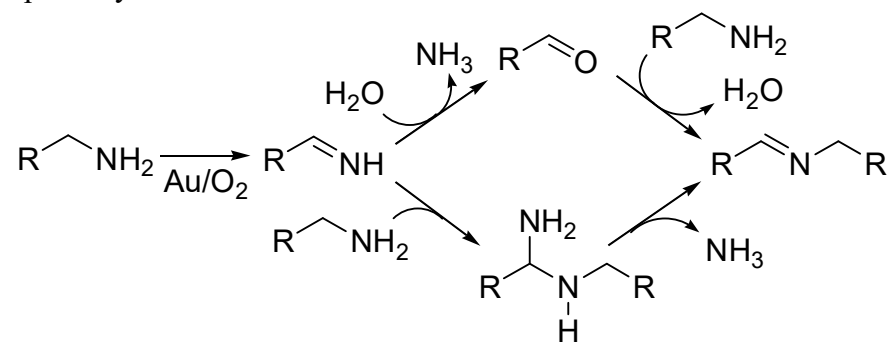

Scheme 2. Proposed reaction pathways for the gold-catalyzed aerobic oxidation of primary amines to imines.

Following the work of Angelici and co-workers, there has been a surge of interest in using gold nanoparticles as catalyst. ${ }^{[6 a]}$ Garcia and co-workers have shown that both the gold crystallite size and the solid support play a crucial role in the catalytic efficiency. ${ }^{[6 b]}$ This increases exponentially as the average particle size is reduced. For example, full conversion of benzylamine to $\mathrm{N}$-benzylidene benzylamine was observed in toluene, at $100{ }^{\circ} \mathrm{C}$, under 1 atm of molecular oxygen, with gold nanoparticles $(3.5 \mathrm{~nm}$ size) supported on $\mathrm{TiO}_{2}$, whereas no conversion was obtained with $25 \mathrm{~nm}$ particle size $\mathrm{Au} / \mathrm{TiO}_{2}$. Furthermore, the reaction rate was more than one order of magnitude larger for gold supported on active carbon $(0.8 \% \mathrm{Au} / \mathrm{C})$ than for $\mathrm{Au} / \mathrm{TiO}_{2}$. Interestingly, $\mathrm{Au} / \mathrm{C}$ could be easily utilized for the oxidation of heterocyclic amines such as pyridin-2ylmethanamine and thiophen-2-ylmethanamine and for the oxidative cross-coupling of benzylamines and amines lacking $\alpha$ hydrogens such as anilines or tert-butylamine (Scheme 3). The cross-coupled products were obtained with almost full conversion and selectivity. ${ }^{[6 b]}$ The proposed mechanism involves the formation of the homocoupled product as the intermediate which, under the reaction conditions, converts to the mixed imines.

$\begin{array}{lll}\mathrm{Ar} \sim \mathrm{NH}_{2} & \begin{array}{l}\mathrm{R}-\mathrm{NH}_{2}(1.5-2 \text { equiv }) \\ \text { toluene, } 100{ }^{\circ} \mathrm{C}\end{array} \\ \mathrm{Ar} & \mathrm{R} & \\ \mathrm{C}_{6} \mathrm{H}_{5} & \mathrm{C}_{6} \mathrm{H}_{5}(5 \mathrm{~atm}) & \\ p-\mathrm{Cl}-\mathrm{C}_{6} \mathrm{H}_{4} & p-\mathrm{Me}-\mathrm{C}_{6} \mathrm{H}_{4} \\ p-\mathrm{Cl}-\mathrm{C}_{6} \mathrm{H}_{4} & t \mathrm{Bu} \\ p-\mathrm{Me}-\mathrm{C}_{6} \mathrm{H}_{4} & t \mathrm{Bu} \\ \mathrm{Py} & p-\mathrm{Me}-\mathrm{C}_{6} \mathrm{H}_{4}\end{array}$

Scheme 3. Oxidative cross-coupling of benzylic amines and primary amines lacking $\alpha$-hydrogens.

The selective aerobic oxidation of benzylamine substrates to $\mathrm{N}$ benzylidenebenzylamine has also been studied using nanogold catalysts supported on graphite $(14.5 \mathrm{~nm}$ size $),{ }^{[6 \mathrm{c}]}$ and ceria. ${ }^{[6 \mathrm{~d}]} \mathrm{In}$ the latter case, the catalyst precursors, $\mathrm{Au}(\mathrm{OAc})_{3}$ and $\mathrm{CeO}_{2}$ support, were added to the reaction mixture and the active gold nanoparticles $\left(\mathrm{Au} / \mathrm{CeO}_{2}\right)$ were generated in situ.

\section{Copper-catalyzed aerobic oxidation}

The major drawback of gold as a catalyst is its high price. Recently, green processes have been developed that use cheap, easily available and biocompatible transition-metal catalysts with dioxygen, or more preferably air as the sole oxidant. Patil and Adimurthy have reported the first efficient synthesis of imines from diverse primary benzylic amines using air as the oxidant, under solvent-free conditions with low $\mathrm{Cu}(\mathrm{I})$ catalyst loadings (Table 2) ${ }^{[7 \mathrm{a}]}$ However, in most cases, 5 to $22 \%$ of aldehyde were also isolated as the by-product. Interesting, $n$-hexylamine could be converted in reasonable yield $(50 \%)$ under these experimental conditions. Heterocoupled imines could also be prepared by reacting benzylamines with different anilines, but the degree of selectivity was low and, in some cases, $N$-benzylidene benzylamine was the major product. The proposed mechanism for the formation of homocoupled imines involves the formation of a complex of $\mathrm{Cu}(\mathrm{II})$, resulting from the oxidative addition of $\mathrm{Cu}(\mathrm{I})$ with amine. Further oxidation of this complex provides the methanimine intermediate $\mathrm{RCH}=\mathrm{NH}$, which then reacts according to scheme 2 . To avoid the formation of aldehyde by-product, Patil and Adimurthy reported a variant of their initial procedure in which copper powder $(0.5 \mathrm{~mol}-\%)$ was used as the heterogeneous catalyst. Then, full conversion of benzylamine to $N$-benzylidene benzylamine was obtained under neat conditions and atmospheric 
oxygen at $90{ }^{\circ} \mathrm{C} \cdot{ }^{[7 b]}$ This method was sufficiently general to accommodate a variety of substituents. Both electron-rich and electron-poor benzylic substrates were well-tolerated, producing imines in good to excellent yields $(60-90 \%)$. In particular, the $p$ chloro coupled imine was isolated in better yield (89\%) compared to the method of Angelici and co-workers. ${ }^{[5 b]}$ This simple $\mathrm{Cu}(0)$ catalytic system can oxidize benzylic amines to imines efficiently but moderately aliphatic amines such as pentylamine for which the yield of imine was found to be $34 \%$. Furthermore, a relatively high temperature is required $\left(90^{\circ} \mathrm{C}\right)$.

Table 2. Copper-catalyzed aerobic oxidation of benzylic amines to imines.

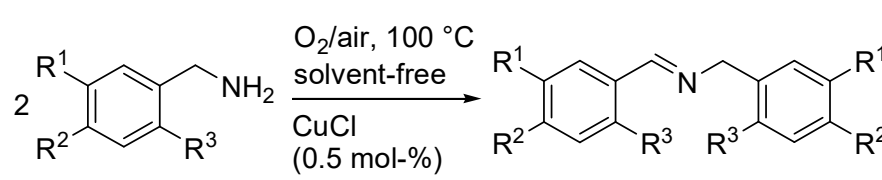

\begin{tabular}{lllll}
\hline Entry & $\mathrm{R}^{1}$ & $\mathrm{R}^{2}$ & $\mathrm{R}^{3}$ & ${\text { Yield [\%] }]^{[\mathrm{a}]}}$ \\
\hline 1 & $\mathrm{H}$ & $\mathrm{H}$ & $\mathrm{H}$ & 82 \\
2 & $\mathrm{H}$ & $\mathrm{Me}$ & $\mathrm{H}$ & 80 \\
3 & $\mathrm{H}$ & $\mathrm{H}$ & $\mathrm{Me}$ & 67 \\
4 & $\mathrm{H}$ & $\mathrm{OMe}$ & $\mathrm{H}$ & 72 \\
5 & $\mathrm{H}$ & $\mathrm{F}$ & $\mathrm{H}$ & 72 \\
6 & $\mathrm{H}$ & $\mathrm{H}$ & $\mathrm{Cl}$ & 85 \\
7 & $\mathrm{Cl}$ & $\mathrm{H}$ & $\mathrm{H}$ & 76 \\
8 & $\mathrm{H}$ & $\mathrm{Cl}$ & $\mathrm{H}$ & 89 \\
9 & $\mathrm{H}$ & $\mathrm{H}$ & $\mathrm{F}$ & $52^{[\mathrm{b}]}$ \\
10 & $\mathrm{~F}$ & $\mathrm{H}$ & $\mathrm{H}$ & $54[\mathrm{~b}]$ \\
\hline
\end{tabular}

[a] Yield of isolated imines. [b] Rest of starting fluorobenzylamine was recovered.

Recently, $\mathrm{Hu}$ and Kerton have reported that the synergistic combination of electron-deficient 2,2,6,6,-tetramethyl-1-piperidyl1-oxy radical (TEMPO) redox mediator and copper(II) bromide was able to oxidize benzylic amines to imines, at room temperature under atmospheric conditions (Table 3). ${ }^{[7 c]}$ However, attempts made to oxidize $n$-hexylamine were almost unsuccessful since only a small amount of the corresponding imine (5\%) was detected. Benzylamines could also react with anilines to afford $\mathrm{N}$ benzylidene anilines with moderate to good conversions but the oxidative coupling reactions proceeded smoothly with 7.5 mol- $\%$ catalyst loading, at $45^{\circ} \mathrm{C}$ under air. ${ }^{[7 \mathrm{c}]}$

Table 3. $\mathrm{CuBr}_{2} / \mathrm{TEMPO}$ catalyzed oxidation of primary benzylic amines.

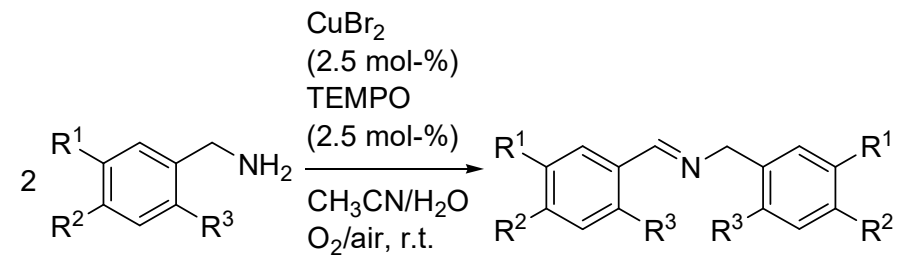

\begin{tabular}{lllll}
\hline Entry & $\mathrm{R}^{1}$ & $\mathrm{R}^{2}$ & $\mathrm{R}^{3}$ & Yield [\%] $^{[\mathrm{a}]}$ \\
\hline 1 & $\mathrm{H}$ & $\mathrm{H}$ & $\mathrm{H}$ & 87 \\
2 & $\mathrm{H}$ & $\mathrm{H}$ & $\mathrm{OMe}$ & 94 \\
3 & $\mathrm{OMe}$ & $\mathrm{H}$ & $\mathrm{H}$ & 93 \\
4 & $\mathrm{H}$ & $\mathrm{OMe}$ & $\mathrm{H}$ & 94 \\
5 & $\mathrm{H}$ & $\mathrm{H}$ & $\mathrm{Me}$ & 93 \\
6 & $\mathrm{H}$ & $\mathrm{Me}$ & $\mathrm{H}$ & 88 \\
7 & $\mathrm{H}$ & $\mathrm{H}$ & $\mathrm{Cl}$ & 82 \\
8 & $\mathrm{H}$ & $\mathrm{Cl}$ & $\mathrm{H}$ & 76 \\
\hline
\end{tabular}

[a] Yield of isolated imines.
Besides, Kanai and co-workers have described a modification of the above protocol using a less sterically demanding and more electron-poor $N$-oxyl radical than TEMPO. This radical (ketoABNO) acts in cooperation with copper(I) bromide to lead excellent yields of homocoupled imines from some primary benzylic amines but with long reaction times (Table 4). Mechanistic studies suggest that the oxidation reaction proceeds through sequential or concerted [1e $+1 \mathrm{e}]$ abstraction from benzylic amines by a $\mathrm{Cu}(\mathrm{II}) / \mathrm{N}-\mathrm{Oxyl}$ radical complex. ${ }^{[7 \mathrm{~d}]}$

Table $4 . \mathrm{CuBr} /$ ketoABNO catalyzed oxidation of primary benzylic amines.

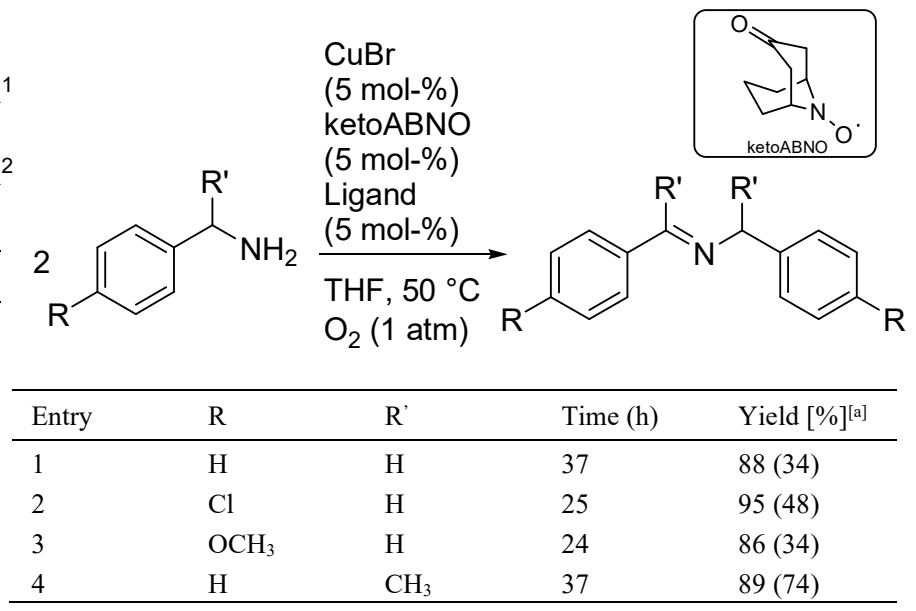

[a] The yields were determined as combined yields of imines and hydrolyzed aldehydes. The values in parentheses are isolated imine yields after alumina column chromatography.

\section{Other transition metal-catalyzed oxidation}

In addition to the extensively studied gold and copper systems, a number of methods using other transition metal have been recently reported. Garcia and co-workers have developed a system based on an iron metal-organic framework (MOF) solid for the direct oxidation of benzylic amines to imines with molecular oxygen, at $100{ }^{\circ} \mathrm{C}$, under solvent-free conditions. ${ }^{[\mathrm{a}]}$ The heterogeneous catalyst used consists of $\mathrm{Fe}$ [1,3,5-benzenetricarboxylate (BTC)] incorporating N-hydroxyphtalimide (NHPI). This system competes with other heterogeneous catalysts such as supported gold nanoparticles and avoids the use of noble metals and solvents. However, the $\mathrm{Fe}(\mathrm{BTC}) / \mathrm{NHPI}$ system failed to oxidize aliphatic amines such as n-hexylamine, whereas supported gold nanoparticles can do that. Clean oxidation of primary benzylamines to imines has also been successfully achieved by Chu and Li using hydrogen peroxide as a green oxidant catalyzed by inexpensive and stable vanadium oxide, in water at room temperature. ${ }^{[8 b]} \mathrm{High}$ yields of homocoupled imines were obtained from the catalytic oxidation of mono- and bi-substituted benzylamine substrates bearing electron-withdrawing groups (Table 5), whereas no imines were obtained from benzylamines bearing electron-donating groups. Instead, benzylic aldehydes could be prepared in good yields (66-78\%), when the reaction mixture was heated to $50{ }^{\circ} \mathrm{C}$. Ogawa and co-workers have also described a vanadium catalyst ( 2 mol-\%) for the oxidation of substituted benzylamines to imines, in acetonitrile, at $120{ }^{\circ} \mathrm{C}$, under the atmosphere of molecular oxygen. ${ }^{[8 \mathrm{c}]}$ Interesting, the vanadium catalyst could be reused up to eight times without loss of activity when working in ionic liquids. 


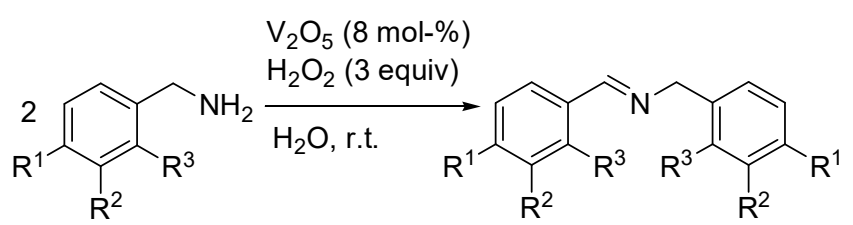

\begin{tabular}{lllll}
\hline Entry & $\mathrm{R}^{1}$ & $\mathrm{R}^{2}$ & $\mathrm{R}^{3}$ & Yield [\%] ${ }^{[\mathrm{a}]}$ \\
\hline 1 & $\mathrm{H}$ & $\mathrm{H}$ & $\mathrm{H}$ & 64 \\
2 & $\mathrm{Cl}$ & $\mathrm{H}$ & $\mathrm{H}$ & 91 \\
3 & $\mathrm{H}$ & $\mathrm{F}$ & $\mathrm{H}$ & 75 \\
4 & $\mathrm{H}$ & $\mathrm{H}$ & $\mathrm{Cl}$ & 80 \\
5 & $\mathrm{H}$ & $\mathrm{Cl}$ & $\mathrm{H}$ & 76 \\
6 & $\mathrm{H}$ & $\mathrm{Br}$ & $\mathrm{H}$ & 87 \\
7 & $\mathrm{H}$ & $\mathrm{Cl}$ & $\mathrm{Cl}$ & 99 \\
8 & $\mathrm{Cl}$ & $\mathrm{H}$ & $\mathrm{Cl}$ & 83 \\
9 & $\mathrm{CO}{ }_{2} \mathrm{Et}$ & $\mathrm{H}$ & $\mathrm{H}$ & 66 \\
10 & $\mathrm{H}$ & $\mathrm{NO}_{2}$ & $\mathrm{H}$ & 78 [b] \\
\hline
\end{tabular}

[a] Yield of isolated imines. [b] all the conversions were $100 \%$ except for entry $10(50 \%)$.

Albrecht and co-workers have explored the catalytic efficiency of a ruthenium(II) complex comprising an imidazolylidene ligand for the dehydrogenation of primary benzylic amines to imines. With 5 mol- $\%$ catalyst loading, the catalytic oxidation took place in toluene, at $150{ }^{\circ} \mathrm{C}$, without the need of any auxiliary base. ${ }^{[8 \mathrm{~d}]}$ Noteworthy, aliphatic amines such as $n$-hexylamine and $n$ butylamine were effectively oxidized, albeit at a lower rate. Similarly, Huang and co-workers have reported a dehydrogenative homocoupling of various primary benzylic amines to form imines, using ruthenium pincer complexes whose the reactivity was enhanced through the introduction of an imine arm to the pincer ligand. ${ }^{[8 \mathrm{e}]}$ High yields of the imine products $(65-93 \%)$ were obtained using $1 \mathrm{~mol}-\%$ of ruthenium pincer complex in toluene, at $115{ }^{\circ} \mathrm{C}$, under argon. Most significantly, with ruthenium complexes, the catalytic oxidation could be performed in the absence of oxidant allowing the limitation of waste.

\section{Metal-free Catalyzed Oxidation Reaction}

The limited availability of precious and rare metal catalysts and their high price has lead to the development of alternative metalfree catalytic systems, but they remain scarce. Fu and co-workers have described a green protocol for the chemoselective aerobic oxidation of primary benzylic amines to imines by simply refuxing suspensions of water and benzylamine substrates under one atmosphere dioxygen. ${ }^{[9]}$ Furthermore, thiophen-2-ylmethanamine and sterically hindered benzhydrylamine could be effectively converted into the homocoupled imines in $65 \%$ and $51 \%$ yields, respectively (Table 6 , entries 8 and 9).

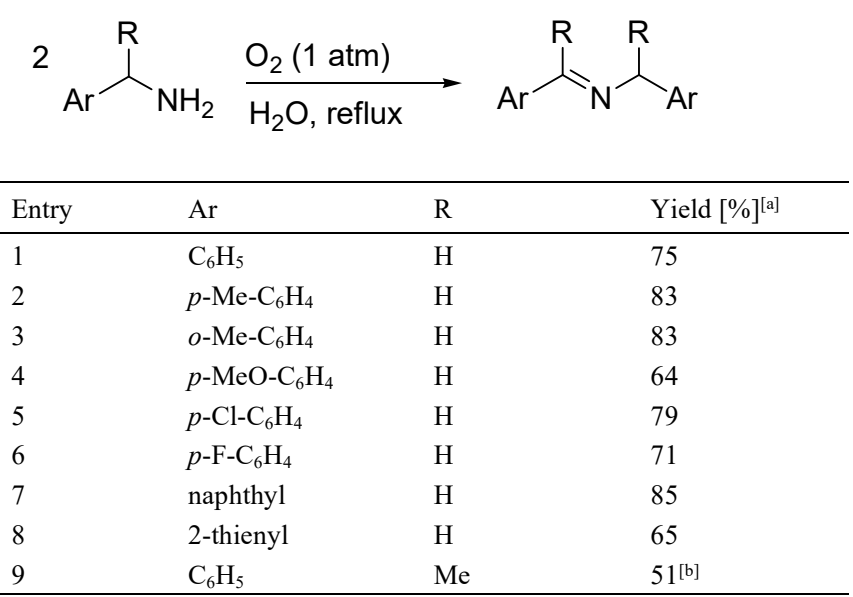

[a] GC yield of imines, the conversions $>95 \%$. [b] $15 \%$ benzophenone was formed, selectivity $=77 \%$.

Whereas aliphatic primary amines had low activity toward oxidative homocoupling reaction, the oxidative cross-coupling of excess aliphatic amines ( 3 equiv) with benzylamine could be performed selectively leading to $\mathrm{N}$-benzylidene alkylimines in roughly $50 \%$ yields (Scheme 4 ). $N$-benzylidene anilines could also be prepared in good yields (around 70\%). The unique weakness of the process was the prolonged reaction times (1-2 days) required for its development.

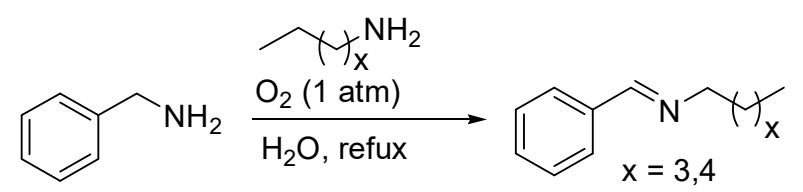

Scheme 4. Aerobic oxidative cross-coupling of amines in refluxing water.

The facile separation of the imines from water led to the use of these compounds as dienophiles in aza Diels-Alder reactions. Imines were mixed with a methanolic solution of Danishefski's diene to form $N$-alkyl-4-pyridone in good yields (Scheme 5). ${ }^{[9]}$ This methodology should allow to expand the scope of the synthesis of $\mathrm{N}$-alkyl-4-pyridones.

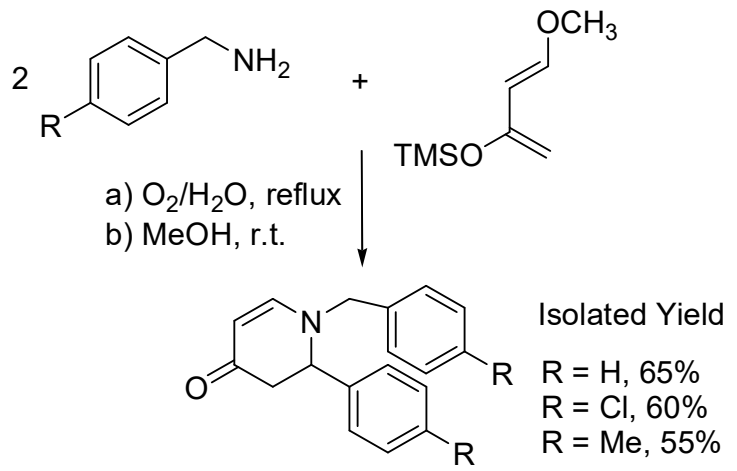

Scheme 5. Tandem oxidative aza Diels-Alder reaction affording $N$-alkyl-4pyridone derivatives.

Because of its low cost and natural abundance, the use of carbon catalysts has received great attention as a green alternative to precious metal catalysts. ${ }^{[10 \mathrm{a}]}$ Graphite oxide (GO)-catalyzed amine 
oxidation was explored by Huang and co-workers. High catalytic activity was found for the conversion of diverse benzylic amines using 50 wt.- $\%$ loading $\mathrm{GO}$ and $5 \mathrm{~atm}$ oxygen pressure at $100{ }^{\circ} \mathrm{C}$, under solvent-free conditions, and the homocoupled imine product yield did not markedly depend on the substitution of the phenyl ring (Table 7 , entries $1-6) \cdot{ }^{[10 b]}$

Table 7. GO-catalyzed aerobic oxidation of benzylic amines.

$$
\begin{aligned}
& \text { GO (50 wt.-\%) } \\
& 2 \curvearrowright \mathrm{RH}_{2} \underset{\text { solvent-free }}{\stackrel{\mathrm{O}_{2}(5 \mathrm{~atm})}{\longrightarrow}} \stackrel{\mathrm{R}}{\mathrm{N}_{\mathrm{N}}} \widehat{\mathrm{R}}_{\mathrm{R}} \\
& 100^{\circ} \mathrm{C}
\end{aligned}
$$

\begin{tabular}{llll}
\hline Entry & $\mathrm{R}$ & Conversion [\%] & Yield [\%] ${ }^{[\mathrm{a}]}$ \\
\hline 1 & $\mathrm{C}_{6} \mathrm{H}_{5}$ & 99 & $98(91)$ \\
2 & $p-\mathrm{Me}-\mathrm{C}_{6} \mathrm{H}_{4}$ & 99 & 97 \\
3 & $o-\mathrm{MeO}-\mathrm{C}_{6} \mathrm{H}_{4}$ & 84 & 80 \\
4 & $m-\mathrm{MeO}-\mathrm{C}_{6} \mathrm{H}_{4}$ & 91 & 88 \\
5 & $p-\mathrm{MeO}-\mathrm{C}_{6} \mathrm{H}_{4}$ & 99 & $98(92)$ \\
5 & $p-\mathrm{Cl}-\mathrm{C}_{6} \mathrm{H}_{4}$ & 95 & 89 \\
6 & $p-\mathrm{F}-\mathrm{C}_{6} \mathrm{H}_{4}$ & 96 & 88 \\
7 & $2-$ pyridyl & 97 & $96(90)$ \\
8 & $2-$ furyl & 93 & 88 \\
9 & $n$ Hex & n.r. & - \\
\hline
\end{tabular}

[a] GC yield of imines, numbers in parenthesis refer to yields of isolated products. n.r. no reaction.

Furthermore, heterocyclic amines containing nitrogen and sulfur atoms, which usually deactivate most transition-metal complexes, could be converted into the corresponding imines in high yields (Table 7, entries 7 and 8). Nevertheless, attempts to oxidize simple aliphatic amines such as $n$-hexylamine were unsuccessful (Table 7 , entry 9). On the other hand, this eco-friendly protocol allowed the oxidative cross condensation of benzylamine with various anilines and aliphatic amines. With an excess of aniline (4 equiv), the selectivity towards $N$-benzylidene aniline increased markedly with minimal formation of $N$-benzylidene benzylamine (Scheme 6).

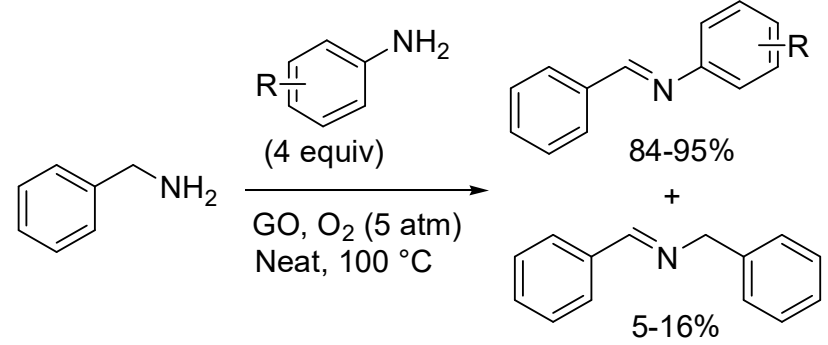

Scheme 6. GO-catalyzed oxidative cross-coupling of benzylamine with anilines.

Loh and co-workers have also discovered a simple chemical processing step to synthesize highly active porous graphene oxide resulting from the exfoliation of graphite oxide. Then, low graphene oxide catalyst loading ( $5 \mathrm{wt} .-\%$ ) was sufficient to catalyze the oxidative homocoupling of primary benzylic amines to imines, at $90{ }^{\circ} \mathrm{C}$, under solvent-free and open-air conditions. ${ }^{[10 \mathrm{c}]}$ High GC yields of imines, ranging from 92 to $98 \%$, were obtained regardless of the presence of electron-donating or electron-withdrawing functionalities. The combination of solvent-free and metal-free catalysis using low graphene oxide catalyst loading open the way for large-scale industrial applications of graphene oxide in industrial catalysis.

Recently, azobisisobutyronitrile (AIBN) has been used by $\mathrm{Fu}$ and co-workers to initiate the chemoselective aerobic oxidation of primary benzylic amines to imines. In the presence of $10 \mathrm{~mol}-\%$ of radical initiator AIBN, good yields of homocoupled imines were obtained from diverse benzylic amines, in toluene at $70{ }^{\circ} \mathrm{C}$, under 1 atm of dioxygen (Table 8). Heterocyclic methylamines containing nitrogen, sulfur and oxygen atoms could also be converted into imines in moderate to good yields (Table 8, entries 7-9). However, the oxidation of aliphatic amines such as cyclohexylamine only produced $7 \%$ of the corresponding imine. The radical chain pathway involves 2-cyano-2-propyloxy radical as the effective

\begin{tabular}{|c|c|c|c|c|}
\hline 2 & \multicolumn{3}{|c|}{$\begin{array}{l}\text { AIBN }(10 \mathrm{~mol}-\% \\
\mathrm{O}_{2}(1 \mathrm{~atm}) \\
\text { toluene, } 70{ }^{\circ} \mathrm{C}\end{array}$} & $A_{A}$ \\
\hline Entry & $\mathrm{Ar}$ & & $\mathrm{R}$ & Yield $[\%]^{[\mathrm{a}]}$ \\
\hline 1 & $\mathrm{C}_{6} \mathrm{H}_{5}$ & & $\mathrm{H}$ & 89 \\
\hline 2 & $p-\mathrm{Me}$ & $\mathrm{e}-\mathrm{C}_{6} \mathrm{H}_{4}$ & $\mathrm{H}$ & 87 \\
\hline 3 & $o-\mathrm{Me}$ & $\mathrm{e}-\mathrm{C}_{6} \mathrm{H}_{4}$ & $\mathrm{H}$ & 88 \\
\hline 4 & $p$-Me & $\mathrm{eO}-\mathrm{C}_{6} \mathrm{H}_{4}$ & $\mathrm{H}$ & 76 \\
\hline 5 & $p-\mathrm{Cl}-$ & $-\mathrm{C}_{6} \mathrm{H}_{4}$ & $\mathrm{H}$ & 85 \\
\hline 6 & $p-\mathrm{F}-\mathrm{C}$ & $\mathrm{C}_{6} \mathrm{H}_{4}$ & $\mathrm{H}$ & 84 \\
\hline 7 & 2-pyr & ridyl & $\mathrm{H}$ & 86 \\
\hline 8 & 2-thic & ienyl & $\mathrm{H}$ & 83 \\
\hline 9 & 2-fur & & $\mathrm{H}$ & 46 \\
\hline 9 & $\mathrm{C}_{6} \mathrm{H}_{5}$ & & $\mathrm{Me}$ & $74^{[\mathrm{b}]}$ \\
\hline
\end{tabular}
initiating species. ${ }^{[11]}$

Table 8. AIBN initiated oxidation of primary benzylic amines to imines.

[a] GC yield of imines, the conversions $>90 \%$. [b] $81 \%$ of conversion.

\section{Photocatalyzed Oxidation Reaction}

The utilization of sunlight as an energy source for chemical transformations has recently attracted much attention. Wang and co-workers have described the aerobic oxidation of benzylic amines to imines, in excellent yields, using a mesoporous graphite carbon nitride $\left(\mathrm{mpg}-\mathrm{C}_{3} \mathrm{~N}_{4}\right)$ photocatalyst with visible light. ${ }^{[12 \mathrm{a}]}$ Complete conversion of benzylamine into $N$-benzylidene benzylamine was obtained in acetonitrile, at $80{ }^{\circ} \mathrm{C}$, in only $2-3 \mathrm{~h}$ but under high oxygen pressure $(0.5 \mathrm{MPa})$. Substituted benzylamines bearing electron-donating groups (Me and $\mathrm{OMe}$ ) were more easily oxidized than those bearing electron-withdrawing groups $\left(\mathrm{Cl}\right.$ and $\left.\mathrm{CF}_{3}\right)$. Pyridin-2-ylmethanamine and thiophen-2ylmethanamine could also be converted into the corresponding imines in excellent yields (95-99\%). After the reaction, the mpg$\mathrm{C}_{3} \mathrm{~N}_{4}$ photocatalyst could be easily separated and reused three times without loss of catalytic activity. Further, the imines resulting from the oxidative coupling reaction could be engaged in situ in an intramolecular cycloaddition and subsequent oxidation to give benzimidazoles and benzothiazoles with high conversion (91-99\%) (Scheme 7). As classical protocols for the synthesis of these heterocycles generally require high temperature or hazardous oxidants, this process would constitute an economically efficient catalytic alternative.

Zhao and co-workers have developed a highly selective photocatalytic oxidation of benzylic amines to imines, in acetonitrile using $\mathrm{TiO}_{2}$ with UV light and 1 atm of air as the oxidant. ${ }^{[12 b]}$ This approach was efficiently applicable to heteroatom-containing amine substrates, such as pyridine thiophene and furan. In contrast, no imines were formed when 
aliphatic primary amines such as cyclohexylamine and nhexylamine were chosen as the substrates.

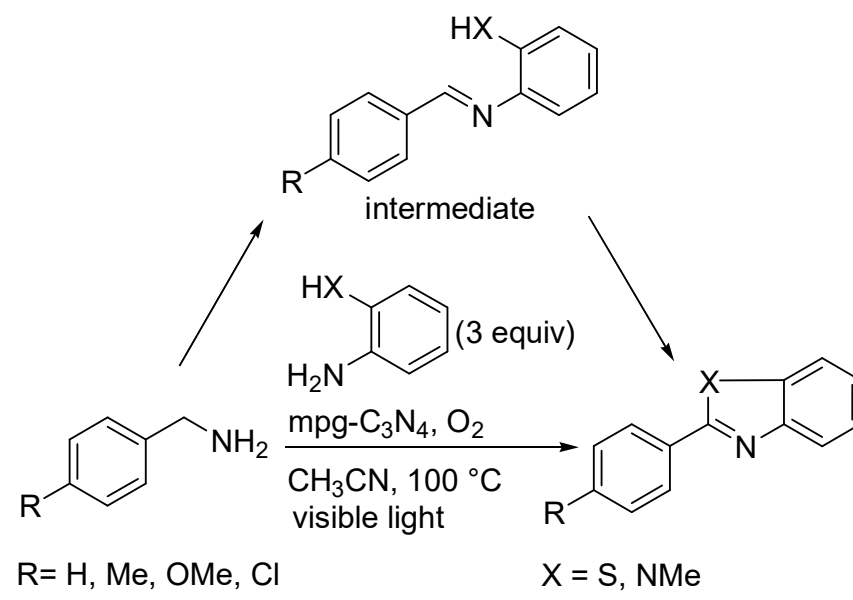

Scheme 7. One-pot aerobic synthesis of benzimidazoles and benzothiazoles mediated by mpg- $\mathrm{C}_{3} \mathrm{~N}_{4}$ photocatalyst.

The proposed reaction mechanism involves a selective oxygenation step to generate the aldehyde whose further condensation with the unreacted amine affords the homocoupled imine (Scheme 8).

$$
\mathrm{Ar} \mathrm{NH}_{2} \stackrel{\mathrm{TiO}_{2} \text {, UV light }}{\mathrm{CH}_{3} \mathrm{CN}, \mathrm{O}_{2} \text { /air }} \longrightarrow
$$

Scheme 8. Proposed mechanism for the $\mathrm{TiO}_{2}$-photocatalyzed oxidation of primary benzylic amines to imines

Although $\mathrm{TiO}_{2}$ is an attractive photocatalytic material because of its low cost and excellent chemical and photochemical stability, it can only be activated by UV-light irradiation. Zhao and co-workers recently discovered that the adsorption of benzylamine on the surface of anatase $\mathrm{TiO}_{2}$ could extent light absorption into the visible range. Thus, diverse benzylic amines including heteroatomcontaining substrates could be oxidized in acetonitrile under $1 \mathrm{~atm}$ of dioxygen, on a surface of anatase $\mathrm{TiO}_{2}$ with visible-light irradiation. Moderate to excellent selectivities for the imines products were achieved in moderate to excellent conversion yields (Table 9). ${ }^{[12 c]}$

Tanaka and co-workers have also reported that, under visible irradiation, niobium oxide can act as an efficient heterogeneous photocatalyst for the aerobic oxidation of various benzylic amines to the corresponding imines in high yields, in benzene, at room temperature, under atmospheric pressure. Electron-rich benzylamines (OMe and Me derivatives) were oxidized faster than electron-poor ones ( $\mathrm{Cl}$ and $\mathrm{CF}_{3}$ derivatives). Interesting, $n$ butylamine could be converted into the corresponding homocoupled imine, but the selectivity $(61 \%)$ was lower than those of benzylic homologues (94-99\%). ${ }^{[12 \mathrm{~d}]}$

Recently, Tada and co-workers have described photocatalysts consisting of gold nanoparticles and metal oxide supports, called "plasmon photocatalysts" for the selective aerobic oxidation of amines to imines. Among various metal oxide used, $\mathrm{Au} / \mathrm{rutile} \mathrm{TiO}_{2}$ exhibited a particularly high level of visible-light activity for the aerobic oxidation of benzylic amines to yield the corresponding imines with high selectivity, at $25{ }^{\circ} \mathrm{C}$, under solvent-free conditions. ${ }^{[12 \mathrm{e}]}$

Table 9. $\mathrm{TiO}_{2}$-photocatalyzed oxidation of primary benzylic amines to imines.

\begin{tabular}{|c|c|c|c|c|}
\hline Entry & $\mathrm{Ar}$ & $\mathrm{R}$ & $\begin{array}{l}\text { Conversion } \\
{[\mathrm{mol} \%]^{[a]}}\end{array}$ & $\begin{array}{l}\text { Selectivity } \\
{[\mathrm{mol} \mathrm{\%}]^{[b]}}\end{array}$ \\
\hline 1 & $\mathrm{C}_{6} \mathrm{H}_{5}$ & $\mathrm{H}$ & 91 & 92 \\
\hline 2 & $p-\mathrm{Me}-\mathrm{C}_{6} \mathrm{H}_{4}$ & $\mathrm{H}$ & 78 & 94 \\
\hline 3 & $p-t \mathrm{Bu}-\mathrm{C}_{6} \mathrm{H}_{4}$ & $\mathrm{H}$ & 90 & 94 \\
\hline 4 & $p-\mathrm{MeO}-\mathrm{C}_{6} \mathrm{H}_{4}$ & $\mathrm{H}$ & 95 & 93 \\
\hline 5 & $p-\mathrm{F}-\mathrm{C}_{6} \mathrm{H}_{4}$ & $\mathrm{H}$ & 84 & 88 \\
\hline 6 & $p-\mathrm{Cl}-\mathrm{C}_{6} \mathrm{H}_{4}$ & $\mathrm{H}$ & 83 & 90 \\
\hline 7 & $o, p-(\mathrm{Cl})_{2}-\mathrm{C}_{6} \mathrm{H}_{3}$ & $\mathrm{H}$ & 92 & 91 \\
\hline 8 & 2-pyridyl & $\mathrm{H}$ & 77 & 86 \\
\hline 9 & 2-furyl & $\mathrm{H}$ & 68 & 38 \\
\hline 10 & 2-thienyl & $\mathrm{H}$ & 77 & 86 \\
\hline 11 & $\mathrm{C}_{6} \mathrm{H}_{5}$ & $\mathrm{Me}$ & 44 & 53 \\
\hline 12 & $p-\mathrm{Br}-\mathrm{C}_{6} \mathrm{H}_{4}$ & $\mathrm{Me}$ & 49 & 49 \\
\hline
\end{tabular}

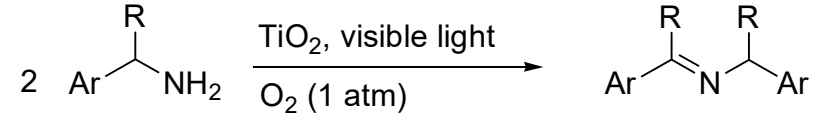

$$
\begin{aligned}
& \mathrm{CH}_{3} \mathrm{CN}
\end{aligned}
$$

[a] Determined by GC analysis. [b] Selectivity = yield/conversion.

\section{Bioinspired Catalyzed Oxidation Reaction}

As can be seen above, significant advances in the oxidation of primary amines have been dominated by the development of catalytic green processes that utilize dioxygen or, more preferably, air as the sole oxidant. In addition, efforts have been made to avoid the use of expensive and limited available precious metal catalysts, energy-consuming processing steps and undesirable reaction media.

The general interest in amine oxidation has also stimulated efforts to mimic the biological activity of copper amine oxidases (CuAOs) owing to their exquisite substrate specificity toward primary amines. ${ }^{[13]} \mathrm{CuAOs}$ couple the oxidation of primary amines to aldehydes with the reduction of dioxygen to hydrogen peroxyde, through the synergistic action of a quinone organic cofactor (TPQ ${ }_{\text {ox }}$ ) and a copper ion. Quinone models that mimic the active site of CuAOs have yielded important insights into the mechanism by which these metalloenzymes operate using benzylamine as the model substrate. ${ }^{[14]}$ Especially, it has been shown that the 4hydroxyl group of $\mathrm{TPQ}_{\mathrm{ox}}$ plays important roles in protecting the quinone ring from ring amination and in directing nucleophilic addition of benzylamine exclusively to the $\mathrm{C}-5$ position (Scheme 9 , step 1). ${ }^{[14 \mathrm{~d}, e]}$ In organic media, the generated Schiff-base intermediate (Scheme 9, step 2) can undergo a direct addition of benzylamine (Scheme 9, step 3) affording the coupled imine product instead of the aldehyde formed in water, together with an aminophenol product (Scheme 9, step 4). Aerobic oxidation of the latter generates the iminoquinone species (Scheme 9, step 5) which undergoes transimination with benzylamine and closes the catalytic cycle (Scheme 9, step 6).

Until recently, the synthetic scope of such reactions had received little attention, although bioinspired catalytic systems would have an advantage over $\mathrm{CuAOs}$ as they might expand the scope of possible substrates and increase the scale of production. Nowadays, the use of CuAOs-like catalytic systems has begun to emerge for the aerobic oxidation of amines to imines in synthetic planning. Especially, efficient metalloenzyme-like catalytic systems have 
been invented that are particularly useful for environmentally friendly catalytic chemistry. ${ }^{[15]}$

Inspired by biochemical model studies, ${ }^{[14 \mathrm{~d}, \mathrm{e}]}$ Wendlandt and Stahl have recently utilized 4-tert-butyl-2-hydroxybenzoquinone (TBHBQ) as an efficient organocatalyst for the chemoselective aerobic oxidative homocoupling of benzylic amines to imines. ${ }^{[16]}$

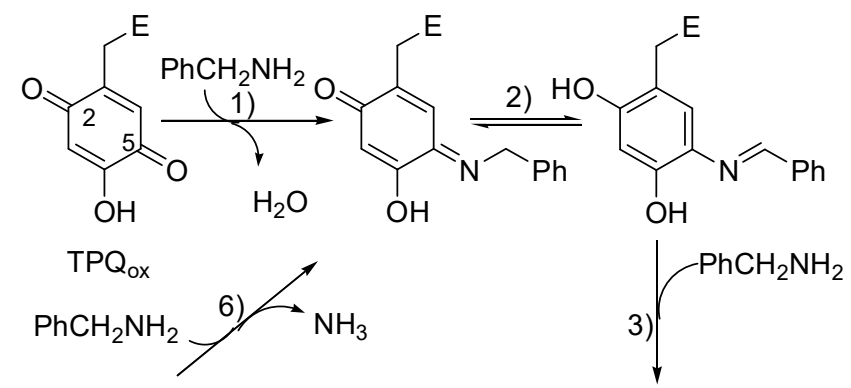

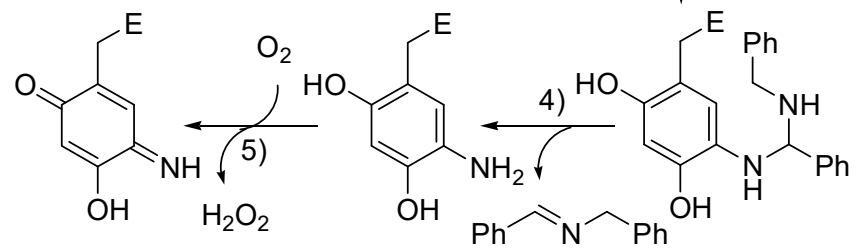

Scheme 9. Proposed ionic transamination mechanism of the aerobic oxidation of primary amines catalyzed by CuAOs quinone models.

High yields of homocoupled imines (Table 10) were found for the conversion of variously substituted benzylic primary amines including the heterocyclic furfurylamine (Table 10, entry 12), in acetonitrile, at room temperature, under 1 atm of molecular oxygen. The imine product yield did not markedly depend on the substitution of the phenyl ring (Table 10, entries 2-11), at the exclusion of more electron-deficient benzylamines bearing $p$ trifluoromethyl and $m$-chloro substituents which were oxidized more slowly and required $48 \mathrm{~h}$ for complete conversion (Table 10, entries 6 and 7). Note the free amino group of $p$-aminobenzylamine does not inhibit dimerization (Table 10 , entry 2 ).

Table 10. Quinone-mediated aerobic oxidation of primary benzylic amines.

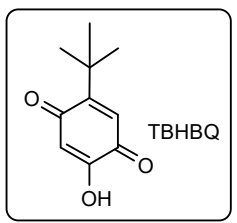

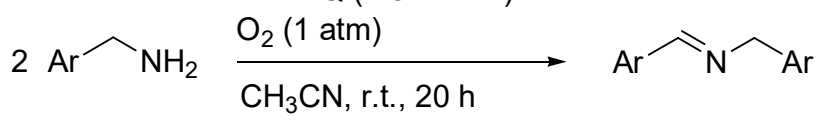

\begin{tabular}{lll}
\hline Entry & $\mathrm{Ar}$ & Yield [\%] $]^{[\mathrm{a}]}$ \\
\hline 1 & $\mathrm{C}_{6} \mathrm{H}_{5}$ & 87 \\
2 & $p-\mathrm{NH}_{2}-\mathrm{C}_{6} \mathrm{H}_{4}$ & 76 \\
3 & $p-\mathrm{MeO}-\mathrm{C}_{6} \mathrm{H}_{4}$ & 93 \\
4 & $p-\mathrm{Cl}-\mathrm{C}_{6} \mathrm{H}_{4}$ & 90 \\
5 & $p-\mathrm{F}-\mathrm{C}_{6} \mathrm{H}_{4}$ & 91 \\
6 & $p-\mathrm{CF}_{3}-\mathrm{C}_{6} \mathrm{H}_{4}$ & $78^{[\mathrm{b}]}$ \\
7 & $m-\mathrm{Cl}^{-} \mathrm{C}_{6} \mathrm{H}_{4}$ & $72^{[\mathrm{b}]}$ \\
8 & $m-\mathrm{I}-\mathrm{C}_{6} \mathrm{H}_{4}$ & 70 \\
9 & $o-\mathrm{Me}-\mathrm{C}_{6} \mathrm{H}_{4}$ & 86 \\
10 & $o-\mathrm{MeO}-\mathrm{C}_{6} \mathrm{H}_{4}$ & 73 \\
11 & naphthyl & 81 \\
12 & 2 -furyl & 80 \\
\hline
\end{tabular}

[a] Yield of imines determined by ${ }^{1} \mathrm{H}$ NMR spectroscopy versus internal standard. [b] Reaction time was $48 \mathrm{~h}$.
As for the CuAOs, secondary amines and tertiary amines were not oxidized under the same experimental conditions. The chemoselectivity for primary amines could be easily explained by the ionic transamination process (Scheme 9), which has been elucidated in previous biochemical model studies. ${ }^{[14]}$ However, TBHBQ failed to oxidize aliphatic primary amines, but the exclusive selectivity for benzylic primary amines allowed selective formation of heterocoupled amines in high yields (Table 11). As a significant advantage over transition-metal catalyzed reactions, primary amines bearing alcohol or amine functionalities underwent effective heterocoupling with benzylamine, without oxidation of the alcohol or amine fragment (Table 11, entries 5 and 6).

Table 11. Quinone-mediated aerobic cross-coupling of primary amines

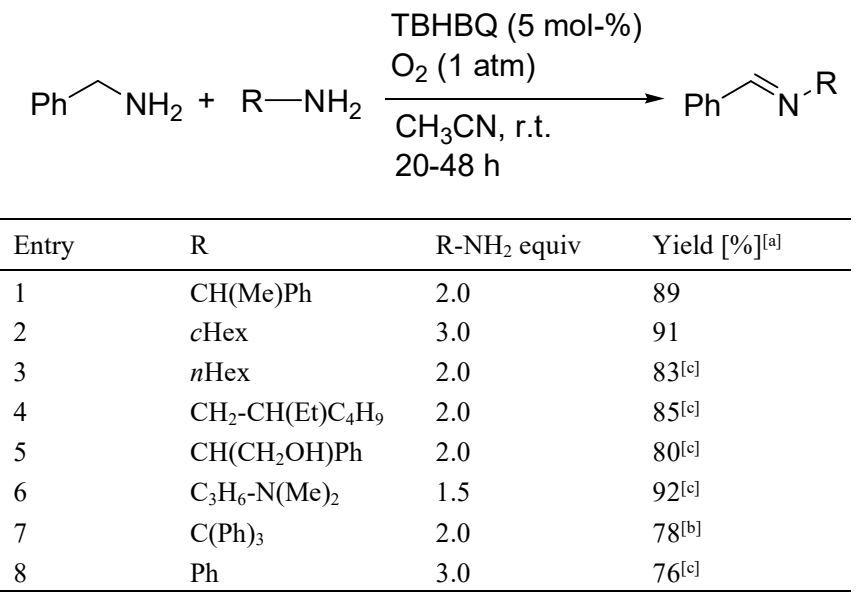

[a] Yield of imines determined by ${ }^{1} \mathrm{H}$ NMR spectroscopy versus internal standard. [b] Isolated yield. [c] After 24 h, 5 mol-\% of TBHBQ was added, and the reaction was run for additional $24 \mathrm{~h}$.

Our group has also described an $o$-iminoquinone species (IMQ) that acts as an effective biomimetic catalyst for the chemoselective oxidation of primary amines under mild conditions. Unstable IMQ was electrogenerated, at room temperature, from the corresponding $o$-aminophenol derivative through anodic-controlled potential electrolysis at a platinum anode, in deaerated methanol containing the primary amine. ${ }^{[17 \mathrm{a}]}$ Interesting, IMQ $(2 \mathrm{~mol} \%)$ was able to replicate the activity and specificity of $\mathrm{CuAOs}$ toward primary amines whereas no activity was observed with secondary and tertiary amines. ${ }^{[17 b]}$ In contrast to quinone models cofactors, IMQ was also active on aliphatic amines, especially on diverse endogenous mono- and polyamines which are substrates for CuAOs enzymes. ${ }^{[17 \mathrm{c}, \mathrm{d}]}$ The reaction pathway was very close to the ionic transamination process reported for $\mathrm{CuAOs}$ cofactors (Scheme 9). The formation of a highly reactive Schiff base cyclic transition state (Scheme 10), which allowed the activation of the imine function for further nucleophilic attack by the amine, constituted a driving force for the overall transamination mechanism. ${ }^{[17 \mathrm{~b}]}$ The catalytic cycle produced the $o$-aminophenol reduced catalyst and the homocoupled imine as the product of amine oxidation, at room temperature, leaving ammonia as the sole by-product.

However, the experimental conditions used for the anodic electrolysis did not allow the isolation of imines products due to their instability during work-up. In return, their formation was indirectly demonstrated by using the imine in situ for further reactions. 
<smiles>COc1ccc(C(C)=O)c(O)c1N</smiles>

(2 $\mathrm{mol}-\%)$

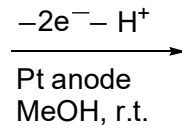<smiles>CC(=O)C1=C(O)C(=N)C(=O)C=C1</smiles><smiles>[R]CNC(C)C</smiles><smiles>[R]CN1CCCC1Nc1c(OC)ccc(C(C)=O)c1O</smiles><smiles>CCCCCCCC</smiles><smiles></smiles>

Schiff base cyclic transition state

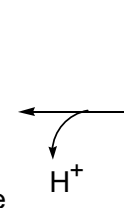<smiles>[R]CN=C1C(=O)C=CC(C(C)=O)=C1O</smiles>

Scheme 10. Ionic transamination pathway of catalytic oxidation of primary amines mediated by electrogenerated $o$-iminoquinone $\mathrm{CuAOs}$ mimic.

For example, we have recently developed a facile one-pot metal-free IMQ-mediated oxidation-imine formation-reduction sequence for the atom-economical chemoselective $\mathrm{N}$-alkylation of benzylic primary amines with amines, allowing, under mild conditions, the synthesis of benzylic secondary amines in good yields $(60-80 \%)$. This methodology could also be applied to aliphatic primary amines but the yield of the corresponding secondary amine was lower $(50 \%)$ than that expected on the basis of the high current efficiency ( $95 \%$ for $3 \mathrm{~h}$ ), probably as a result of the lower stability of the produced secondary alkylamine during workup. ${ }^{[18]}$<smiles>CC(=O)c1ccc(O)c(N)c1O</smiles>

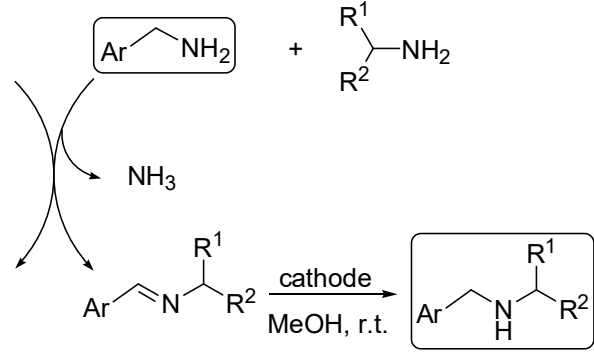

Scheme 11. Electrocatalyzed N-alkylation of benzylic primary amines with aliphatic primary amines.

Inspired by the enzymatic reaction of $\mathrm{CuAOs}$ and by recent breakthroughs on the aerobic oxidation of amines to imines, we have further envisioned some modifications of our initial electrochemical procedure in order to isolate the homocoupled imines, and have shown that a synergistic combination of copper salt and organocatalyst IMQ constituted an attractive approach to imines from primary amines, under very mild conditions that are dioxygen in air as the oxidant together with ambient temperature and pressure. ${ }^{[19]}$ The oxidation process started with atmospheric oxygen as reported in Scheme 12, and continued in a cascade-like manner by passing its oxidation potential through copper salt to the

organic $o$-iminoquinone mediator IMQ, which finally oxidized the amine substrate after forming the Schiff base cyclic transition state shown in Scheme 10. Low catalytic amounts of biocompatible $\mathrm{Cu}(\mathrm{I})$ metal-catalyst $(0.2 \mathrm{~mol}-\%)$ and IMQ organocatalyst $(2 \mathrm{~mol}-$ $\%$ ) were sufficient to activate the $\alpha-\mathrm{C}-\mathrm{H}$ bond of primary amines which were converted into alkylated imines under ambient conditions. High yields of homocoupled imines were obtained from various benzylic amines regardless of the electronic and/or steric effects of the substituents (Table 12, entries 1-7). Heterocyclic amines containing nitrogen and sulfur atoms could be converted efficiently into the corresponding imines. (Table 12, entries 8 and 9). In addition, the cooperative catalytic system was also able to oxidize aliphatic primary amines (Table 12 , entries 10-12).

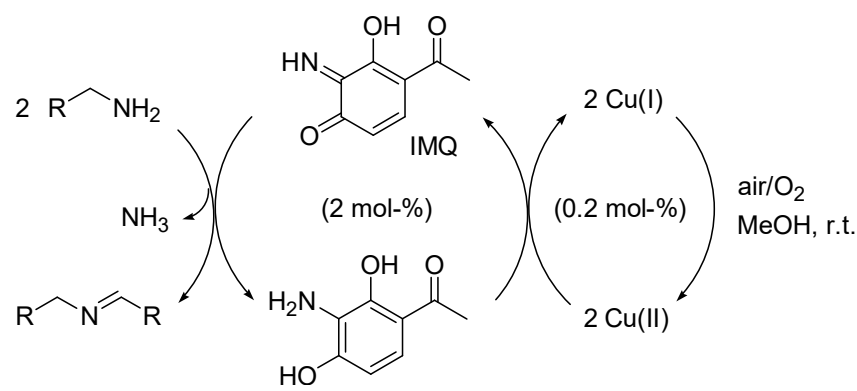

Scheme 12. Aerobic oxidation of primary amines to imines catalyzed by the bioinspired $\mathrm{Cu}(\mathrm{I}) / \mathrm{IMQ}$ system.

Interesting, this atom economical green process was also highly selective in the case of cross-coupling of benzylic amines with aliphatic amines. ${ }^{[19]}$

Table 12. $\mathrm{Cu}(\mathrm{I}) / \mathrm{IMQ}$-mediated aerobic oxidation of primary amines.

$$
\begin{aligned}
& \mathrm{Cu} \text { (I) }(0.2 \mathrm{~mol}-\%) / \mathrm{air} \\
& 2 \curvearrowright \mathrm{NH}_{2} \stackrel{\mathrm{IMQ}(2 \mathrm{~mol}-\%)}{\mathrm{MeOH} \text {, r.t., } 10 \mathrm{~h}} \mathrm{R} \widehat{\mathrm{N}} \widehat{\mathrm{R}}_{\mathrm{R}}
\end{aligned}
$$

\begin{tabular}{lll}
\hline Entry & $\mathrm{R}$ & Yield [\%] $]^{[\mathrm{a}]}$ \\
\hline 1 & $\mathrm{C}_{6} \mathrm{H}_{5}$ & 96 \\
2 & $p$ - $\mathrm{F}-\mathrm{C}_{6} \mathrm{H}_{4}$ & 93 \\
3 & $o, p-(\mathrm{Cl})_{2} \mathrm{C}_{6} \mathrm{H}_{3}$ & 90 \\
4 & $p-\mathrm{Me}-\mathrm{C}_{6} \mathrm{H}_{4}$ & 97 \\
5 & $p-t \mathrm{Bu}-\mathrm{C}_{6} \mathrm{H}_{4}$ & 96 \\
6 & $p-\mathrm{MeO}-\mathrm{C}_{6} \mathrm{H}_{4}$ & 95 \\
7 & $m, m-(\mathrm{OMe})_{2}-\mathrm{C}_{6} \mathrm{H}_{3}$ & 85 \\
8 & 2 -thienyl & 88 \\
9 & 2 -furyl & 78 \\
10 & $c \mathrm{Pr}$ & $40^{[\mathrm{b}]}$ \\
11 & $-\mathrm{CH}_{2}-t \mathrm{Bu}$ & $50^{[b]}$ \\
12 & $-\mathrm{CH}_{2} \mathrm{CH}_{2} \mathrm{NH}_{2}$ & $55^{[b]}$ \\
\hline
\end{tabular}

[a] Yields of the imine refer to the isolated unpurified product which was pure determined by ${ }^{1} \mathrm{H}$ NMR spectroscopy. [b] Yields obtained by conversion to the corresponding 2,4-dinitrophenylhydrazone owing to the instability of the produced imine.

Recently, Kobayashi and co-workers have reported the first example of a heterogeneous nanocluster catalyst cooperating with an organocatalyst cofactor, that share some characteristics with CuAOs for the aerobic oxidation of amines. ${ }^{[20]}$ The two catalysts act together to overcome energy barriers along the reaction pathway that neither catalyst can accomplish alone. Their metalloenzyme-like cooperative catalytic system consists of a heterogeneous Pt/Ir bimetallic nanocluster catalyst immobilized on 
a styrene-based copolymer support and 4-tert-butyl-o-quinone (TBBQ) as the redox-active organic cofactor. Although metal nanoclusters have been well established as highly active catalysts for various aerobic oxidations, they have had limited utility in converting amines to imines because they required high temperatures. ${ }^{[21]}$ With this new system, primary benzylic amines were dehydrogenated to imines in good isolated yields (Table 13), at room temperature under $1 \mathrm{~atm}$ of molecular oxygen with the exception of amines possessing electron-withdrawing substituents (Table 13, entries 4 and 5).

However there is an important difference with $\mathrm{CuAOs}$ since secondary amines are also good substrates for this cooperative system while $\mathrm{CuAOs}$ are inactive toward these amines. Whereas the chemoselectivity of CuAOs and that of TBHBQ and IMQ has been readily explained by a transamination process, mechanistic studies have revealed divergence in the reaction pathways. An hydride transfer mechanism traversing through a quinone complexe, that binds to the metal nanocluster surface, has been proposed. ${ }^{[20]}$ Noteworthy, these polymer incarcerated catalysts are suitable for green chemistry in terms of effective use for limited natural resources, because these catalysts can be recovered easily and reused up to five times without loss of activity ( 81 to $87 \%$ for first to fifth uses).

Table 13. Immobilized $\mathrm{Pt} / \mathrm{Ir}$ nanoclusters/TBBQ-catalyzed aerobic oxidation of primary amines to imines.

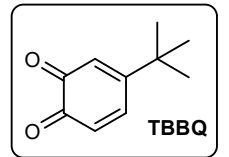

Immobilized Pt/Ir

nanoclusters $(0.5 \mathrm{~mol}-\%)$

$2 \mathrm{Ar} \widehat{\mathrm{NH}_{2}} \underset{\mathrm{CHCl}_{3}: \mathrm{H}_{2} \mathrm{O}(9: 1), 35^{\circ} \mathrm{C}}{\stackrel{\mathrm{O}_{2}(1 \mathrm{~atm}), 16 \mathrm{~h}}{\longrightarrow} \mathrm{Ar}} \widehat{\mathrm{N}}_{\mathrm{Ar}}$

\begin{tabular}{llll}
\hline Entry & $\mathrm{Ar}$ & $\begin{array}{l}\text { Yield [\%] } \\
\text { GC[a] }\end{array}$ & $\begin{array}{l}\text { Yield [\%] } \\
\text { Isolated imine }\end{array}$ \\
\hline 1 & $\mathrm{Ph}$ & 77 & 74 \\
2 & $p-\mathrm{Me}-\mathrm{C}_{6} \mathrm{H}_{4}$ & 80 & 75 \\
3 & $p-\mathrm{MeO}-\mathrm{C}_{6} \mathrm{H}_{4}$ & 80 & 73 \\
4 & $p-\mathrm{Cl}_{2} \mathrm{C}_{6} \mathrm{H}_{4}$ & 60 & 52 \\
5 & $p-\mathrm{CF}_{3}-\mathrm{C}_{6} \mathrm{H}_{4}$ & 57 & 55 \\
\hline
\end{tabular}

[a] Determined by GC analysis using anisole as the internal standard.

Another bioinspired catalytic system that uses metalloporphyrins as chemical models of cytochrome P-450 has been described by Ji and co-workers. In this system, diverse primary amines can be oxidized to homocoupled imines by tert-butyl hydroperoxide $(t \mathrm{BuOOH})$ as the terminal oxidant in the presence of low amounts (0.03 mol-\%) of manganese(III) meso-tetraphenylporphyrin chloride catalyst (MnTPPCl) under ambient conditions. ${ }^{[22 a]}$ Manganese porphyrins were found to be considerably more active than copper, iron, cobalt and ruthenium porphyrin catalysts for the oxidative coupling of benzylamine in toluene at room temperature. As shown in Table 14, variously substituted benzylic amines could be converted to imines with high conversion rate and high selectivity. Interesting, this approach could be effectively applied to the oxidation of aliphatic primary amines such as aminomethylcyclohexane and $n$-hexylamine (Table 14, entries 7 and 8). Mechanistic investigations revealed that the reaction proceeded through a radical process with formation of high valence manganese intermediate. As a greener procedure, the oxidative coupling of benzylic amines has been further realized using water at the solvent heated at $60^{\circ} \mathrm{C}$, in the presence of water-soluble manganese porphyrins $(0.05 \mathrm{~mol} \%)$ and $t$ - $\mathrm{BuOOH}$ as the terminal oxidant. Under these conditions, diversely substituted benzylamines could be successfully converted to imines in up to $76 \%$ isolated yield. ${ }^{[22 \mathrm{~b}]}$

Table 14. Manganese prophyrin-catalyzed oxidation of primary amines to imines.

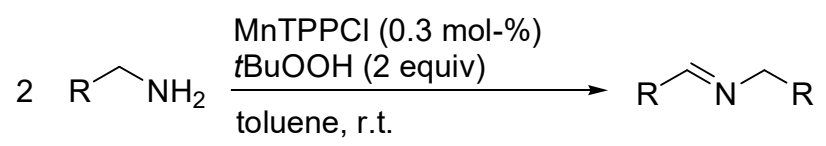

\begin{tabular}{lllll}
\hline Entry & $\mathrm{Ar}$ & Time $(\mathrm{h})$ & Conversion[\%] & Yield[\%] ${ }^{[\mathrm{a}]}$ \\
\hline 1 & $\mathrm{C}_{6} \mathrm{H}_{5}$ & 0.25 & $>99$ & 91 \\
2 & $p-\mathrm{Me}-\mathrm{C}_{6} \mathrm{H}_{4}$ & 1.0 & $>99$ & 88 \\
3 & $p-\mathrm{MeO}-\mathrm{C}_{6} \mathrm{H}_{4}$ & 1.0 & $>99$ & 73 \\
4 & $p-\mathrm{F}-\mathrm{C}_{6} \mathrm{H}_{4}$ & 0.5 & $>99$ & 96 \\
5 & $p-\mathrm{Cl}-\mathrm{C}_{6} \mathrm{H}_{4}$ & 0.5 & 97 & 95 \\
6 & $o, p-(\mathrm{Cl})_{2}-\mathrm{C}_{6} \mathrm{H}_{3}$ & 3.0 & 70 & 57 \\
7 & $c \mathrm{Hex}$ & 2.0 & $>99$ & 91 \\
8 & pentyl & 1.0 & $>99$ & 96 \\
\hline
\end{tabular}

[a] Based on amines, determined by GC and GC-MS.

\section{Conclusion}

In the past few years, new environmentally benign strategies have been identified for the oxidation of primary amines to imines. A significant progress results from the discovery of selective catalytic systems that avoid the utilization of specific oxidants, energy-consuming processing steps and undesirable reaction media. In this respect, the use of low loadings of biocompatible transition metal catalysts or organocatalysts, with dioxygen or air as the sole oxidant, is particularly attractive from the view point of green chemistry. The development of such processes that satisfy environmental constraints is in constant demand by the pharmaceutical and chemical industries.

Many challenges remain however, including the oxidation, under mild conditions, of nonactivated aliphatic primary amines to imines: apart from a few exceptions, the procedures described in this microreview are especially applicable to benzylic amines. The development of recyclable heterogeneous nanocluster catalysts that contain biocompatible rather than rare and precious metals, would also constitute a welcome advance. In particular, the simulation of the functions of metalloenzymes with cooperative catalytic systems should provide environmentally friendly organic synthesis of imines. This strategy constitutes a challenging topic and a key to extend the chemistry of $\mathrm{C}-\mathrm{H}$ bond activation.

\section{Acknowledgments}

Co-workers and students listed in the references [15, 17-19] are greatly acknowledged for their respective research contributions. Also, the author would like to thank C.N.R.S. and Paris Descartes University for financial support. 
[1] For a recent review see: S. Kobayashi, Y. Mori, J. S. Fossey, M. M. Salter, Chem. Rev. 2011, 111, 2626-2704. See also: J. P. Adams, J Chem. Soc. Perkin Trans. 1 2000, 2, 125-139.

[2] For recent examples see: a) M. S. Kwon, S. Kim, S. Park, W. Bosco, R. K. Chidrala, J. Park, J. Org. Chem. 2009, 74, 2877-2879; b) J. W. Kim, J. He, K. Yamaguchi, N. Mizuno, Chem. Lett. 2009, 38 920-921; c) S. Kegnaes, J. Mielby, U. V. Mentzel, C. H. Christensen, A. Riisager, Green Chem. 2010, 12, 1437-1441; d) L. Jiang, L. Jin, H. Tian, X. Yuan, X. Yu, Q. Xu, Chem. Commun. 2010, 47, 10833-10835; e) B. Gnanaprakasam, J. Zhang, D. Milstein, Angew. Chem. Int. Ed. 2011, 122, 1510-1513; f) M. A. Esteruelas, N. Honczek, M. Olivan, E. Onate, M. Valencia, Organometallics 2011 2468-2471; g) Y. Shiraishi, M. Ikeda, D. Tsukamoto, S. Tanaka, T. Hirai, Chem. Commun. 2011, 47, 4811-4813; h) L. Jiang, L. Jin, H. tian, X. Yu, Q. Xu, Chem. Commun. 2011, 47, 10833-10835; i) A.Maggi, R. Madsen, Organometallics 2012, 31, 451-455; j) R. Reddy Donthriri, R. D. Patil, S. Adimurthy, Eur. J. Org. Chem. 2012, 24, 4457-4460; k) H. Tian, X. Yu, Q. Li, J. Wang, Q. Xu, Adv. Synth. Catal. 2012, 354, 2671-2677; 1) J. W. Rigoli, S. A. Moyer, S. D. Pearce, J. M. Schomaker, Org. Biomol. Chem. 2012, 10 1746-1749; m) J. M. Perez, R. Cano, M. Yus, D. J. Ramon, Eur. J. Org. Chem. 2012, 24, 4548-4554; n) Q. Kang, Y. Zhang, Green Chem. 2012, 14, 1016-1019; o) H. Li, X. Wang, M. Wen, Z.-X. Wang, Eur. J. Inorg. Chem. 2012, 31, 5011-5020; p) L. Tang, H. Sun, Y. li, Z. Zha, Z. Wang, Green Chem. 2012, 14, 3423-3428; q) J.-F. Soulé, H. Miyamura, S. Kobayashi, Chem. Commun. 2013, 49, 355-357; r) G. Zhang, S. K. Hanson, Org. Lett. 2013, 15, 650-653.

[3] For recent examples see: a) A. H. Ell, J. S. M. Samec, C. Brasse, J. E. Bäckvall, Chem. Commun. 2002, 1144-1145; b) K. Yamaguchi, N. Mizuno, Angew. Chem. 2003, 115, 1518-1521; Angew. Chem. Int Ed. 2003, 42, 1480-1483; c) K. Yamaguchi, N. Mizuno, Chem. Eur. J. 2003, 9, 4353-4361; d) J. S. M. Samec, A. H. Ell, J. E. Bäckvall, Chem. Eur. J. 2005, 11, 2327-2334; e) J. R. Wang, Y. Fu, B. -B. Zhang, X. Cui, L. Liu, Q.-X. Guo, Tetrahedron Lett. 2006, 47 , 8293-8297; f) H. Choi, M. P. Doyle, Chem. Commun. 2007, 745-747; g) B. Zhu, R. J. Angelici, Chem. Commun. 2007, 2157-2159; h) M. Turner, O. P. H. Vaughan, R. M. Lambert Chem. Commun. 2008, 2316-2317; i) N. Mizuno, K. Yamaguchi, Catal. Today, 2008, 132, 18-26; j) G. Jiang, J. Chen, J.-S. Huang, C.-M. Che, Org. Lett. 2009, 11, 4568-4571; k) R. Yamaguchi, C. Ikeda, Y. Takahashi, K.-I. Fugita, J. Am. Chem. Soc. 2009, 131, 8410-8412; 1) L. Aschwanden, T. Mallat, J.-D. Grunwaldt, F. Krumeich, A. Baiker, J. Mol. Catal. A: Chem. 2009, 300, 111-115; m) L. Aschwanden, T. Mallat, M. Maciejewski, F. Krumeich, A. Baiker, ChemCatChem 2010, 2, 666-673; n) H. Miyamura, M. Morita, T. Inasaki, S. Kobayashi, Bull. Chem. Soc. Jpn. 2011, 84, 588-599; o) E. R. Klobukowski, R. J. Angelici, L. K. Woo, Catal. Lett. 2012, 142, 161-167.

[4] For a recent review see: a) M. T. Schümperli, C. Hammond, I. Hermans, ACS Catal. 2012, 2, 1108-1117 and references therein; see also: b) Y. Maeda, T. Nishimura, S. Uemura, Bull. Chem. Soc. Japan 2003, 76, 2399-2403; c) S. Kamiguchi, A. Nakamura, A. Suzuki, M. Kodomari, M. Nomura, Y. Iwasawa, T. Chihara, J. Catal. 2005, 230 , 204-213; d) F. Li, J. Chen, Q. Zhang, Y. Wang, Green Chem. 2008, 10, 553-562; e) S. Venkatesan, A. S. Kumar, J.-F. Lee, T.-S. Chan, J.-M. Zen, Chem. Eur. J. 2012, 18, 6147-6151.

[5] For a recent review see: a) R. J. Angelici, Catal. Sci. Technol. 2013 3, 279-296; see also: b) B. Zhu, M. Lazar, B. G. Trewyn, R. J. Angelici, J. Catal. 2008, 260, 1-6.

[6] For a recent review see: a) Y. Zhang, X. Cui, F. Shi, Y. Deng, Chem. Rev. 2012, 112, 2467-2505; see also b) : A. Grirrane, A. Corma, $\mathrm{H}$ Garcia, J. Catal. 2009, 264, 138-144; c) M. -H. So, Y. Liu, C.-M. Ho, C.-M. Che, Chem. Asian J. 2009, 4, 1551-1561; d) L. Aschwanden, T. Mallat, F. Krumeich, A. Baiker, J. Mol. Catal. A: Chem. 2009, 309, 57-62.

[7] a) R. D. Patil, S. Adimurthy, Adv. Synth. Catal. 2011, 353 , 1695-1700; b) R. D. Patil, S. Adimurthy, RSC $A d v$. 2012, 2 , 5119-5122; c) Z. Hu, F. M. Kerton, Org. Biomol. Chem. 2012, 10, 1618-1624; d) T. Sonobe, K. Oisaki, M. Kanai, Chem. Sci. 2012, 3, 3249-3255.

[8] a) A. Dhakshinamoorthy, M. Alvaro, H. Garcia, ChemCatChem 2010, 2, 1438-1443; b) G. Chu, C. Li, Org. Biomol. Chem. 2010, 8 , 4716-4719; c) S. Kodama, J. Yoshida, A. Nomoto, Y. Ueta, S. Yano, M. Ueshima, A. Ogawa, Tetrahedron Lett. 2010, 51, 2450-2452; d)
A. Prades, E. Peris, M. Albrecht, Organometallics 2011, 30, 1162-1167; e) L.-P. He, T. Chen, D. Gong, Z. Lai, K.-W. Huang, Organometallics 2012, 31, 5208-5211.

[9] L. Liu, S. Zhang, X. Fu, C.-H. Yan, Chem. Commun. 2011, 47, 10148-10150.

[10] For a recent review see: a) C. Su, K. P. Loh, Acc. Chem. Res. 2013, DOI 10.1021/ar300118v; see also: b) H. Huang, J. Huang, Y.-M. Liu, H.-Y. He, Y. Cao, K.-N. Fan, Green Chem. 2012, 14, 930-934; c) C. Su, M. Acik, K. Takai, J. Lu, S.-J. Hao, Y. Zheng, P. Wu, Q. Bao, T Enoki, Y. J. Chabal, K. P. Loh, Nat. Commun. 2012, 3, 1298-1306.

[11] L. Liu, Z. Wang, X. Fu, C.-H. Yan, Org. Lett. 2012, 14, 5692-5695.

[12] a) F. Su, S. C. Mathew, L. Möhlmann, M. Antonietti, X. Wang, S. Blechert, Angew. Chem. 2011, 123, 683-686; Angew. Chem. Int. Ed. 2011, 50, 657-660; b) X. Lang, H. Ji, C. Chen, W. Ma, J. Zhao, Angew. Chem. 2011, 123, 4020-4023; Angew. Chem. Int. Ed. 2011, 50,3934-3937; c) X. Lang, W. Ma, Y. Zhao, C. Chen, H. Ji, J. Zhao, Chem. Eur. J. 2012, 18, 2624-2631; d) S. Furukawa, Y. Ohno, T. Shishido, K. Teramura, T. Tanaka, ACS catal. 2011, 1, 1150-1153; e) S.-I. Naya, K. Kimura, H. Tada, ACS catal. 2013, 3, 10-13.

[13] For a review see: J. P. Klinman, Chem. Rev. 1996, 96, 2541-2561; For a book see: Copper amine oxidases. Structures, catalytic mechanisms, and role in pathophysiology. (Eds.: G. Floris, B. Mondovi), CRC Press, New-York, 2009

[14] For reviews see: a) M. Mure, S. A. Mills, J. P. Klinman, Biochemistry 2002, 41, 9269-9278; b) M. Mure, Acc. Chem. Res. 2004, 37, 131-139; see also: c) M. Mure, J. P. Klinman, J. Am. Chem. Soc. 1993, 115, 7117-7127; d) M. Mure, J. P. Klinman, J. Am. Chem. Soc. 1995, 117, 8698-8706; e) M. Mure, J. P. Klinman, J. Am. Chem. Soc. 1995, 117, 8707-8718; f)Y. Lee, L. M. Sayre, J. Am. Chem. Soc. 1995, 117, 11823-11828, and references therein; g) S. Itoh, N. Tanaka, S. Haranou, T. Ando, M. Komatsu, Y. Ohshiro, S. Fukuzumi, J. Org. Chem. 1996, 61, 8967-8974; h) K. Q. Ling, J. Kim, L. M. Sayre, J. Am. Chem. Soc. 2001, 123, 9606-9611.

[15] M. Largeron, M.-B. Fleury, Science 2013, 339, 43-44.

[16] A. E. Wendlandt, S. S. Stahl, Org. Lett. 2012, 14, 2850-2853.

[17] a) M. Largeron, A. Neudörffer, M.-B. Fleury, Angew. Chem. 2003 115, 1056-1059; Angew. Chem. Int. Ed. 2003, 42, 1026-1029; b) M. Largeron, A. Chiaroni, M.-B. Fleury, Chem. Eur. J. 2008, 14, 9961003; c) M. Largeron, M.-B. Fleury, M. Strolin Benedetti Org. Biomol. Chem. 2010, 8, 3796-3800; d) M. Largeron, M.-B. Fleury, M. Strolin Benedetti ECS Trans. 2010, 25, 97-103.

[18] a) M. Largeron, M.-B. Fleury, Org. Lett. 2009, 11, 883-886; b) M. Largeron, Electrochim. Acta, 2009, 54, 5109-5115.

[19] M. Largeron, M.-B. Fleury, Angew. Chem. 2012, 124, 5505-5508; Angew. Chem. Int. Ed. 2012, 51, 5409-5412.

[20] H. Yuan, W.-J. Yoo, H. Miyamura, S. Kobayashi, J. Am. Chem. Soc. 2012, 134, 13970-13973.

[21] R. Akiyama, S. Kobayashi, Chem. Rev. 2009, 109, 594-642.

[22] a) Q.-L. Yuan, X.-T. Zhou, H.-B. Ji, Catal. Commun. 2010, 12, 202-206 ; b) X.-T. Zhou, Q.-G. Ren, H.-B. Ji, Tetrahedron Lett. 2012, 53, 3369-3373. 


\section{Entry for the Table of Contents}

\section{Layout 1:}

Recent years have seen the development of several new methods for the catalytic oxidation of primary amines to imines, under mild conditions. This microreview focuses on the major achievements during the last five years.
Catalytic Oxidation of Primary Amines to Imines

\begin{tabular}{ll} 
Metal & \multicolumn{1}{c}{$\begin{array}{l}\text { Bioinspired } \\
\text { catalysis }\end{array}$} \\
$\begin{array}{l}\text { Metal-free } \\
\text { catalysis }\end{array}$ & $\begin{array}{l}\text { Photo } \\
\text { catalysis }\end{array}$
\end{tabular}

Martine Largeron * Page No. - Page No.

Novel Protocols for the Catalytic Oxidation of Primary Amines to Imines

Keywords: Amine / Imine / Oxidation / Metal catalysis / Metal-free catalysis / Photocatalysis / Bioinspired catalysis 